\title{
Well bottom-hole flowing pressure evaluation method in 48 Block of $\mathbf{S}$ Gas field
}

\author{
Qiang-han Feng ${ }^{1}$, Shi-chen Gao ${ }^{2, a}$, Jia-chao Zhang ${ }^{1}$ and Xiao-chuang Ye ${ }^{1}$ \\ ${ }^{1}$ The Third Natural Gas Plant of Changqing Oil-field Constituent Company \\ Xi'an, Shanxi, 710021, China \\ ${ }^{2}$ Mathematical College, China University of Geosciences, Beijing 100083, China \\ aE-mail:2281506@qq.com
}

\begin{abstract}
Keywords: Gas well; bottom-hole pressure; Density of iteration method; bottom-hole liquid. Abstract. Gas well bottom-hole flowing pressure is an important parameter in gas reservoir geological research and evaluation, reserves calculation, evaluation of capacity calculation and dynamic analysis. So, get accurate bottom-hole flowing pressure has significant importance to the production. Through the production analysis of 48 block in the $\mathrm{S}$ gas field, liquid bottom-hole flowing pressure calculating method of the production block were studied. The density of liquid correction iterative method and measured pressure combined were determined to evaluate the bottom-hole pressure for the gas well development and production.
\end{abstract}

\section{Introduction}

48 block is the typical production gas field block of $\mathrm{S}$ gas field, and its production is complex. From the perspective of production, production wells can be divided into pure gas and liquid production wells. From the perspective of gas well production, production wells can be divided into throttle and throttle-free pipe production. The bottom-hole pressure is an important indicator in gas well dynamic analysis, forecasting and optimizing the reasonable working system of Gas reservoir engineering and gas engineering. Access to reservoir pressure and bottom-hole flowing pressure mainly divided into: gauge measurement and calculating through the well-head pressure. For the 48 block production is complex, bottom-hole pressure must be obtained through a variety of sources. Study on gas well with water-producing bottom-hole flowing pressure evaluation is important to stabilize gas production and increase ultimate the efficiency of gas fields.

\section{Different bottom-hole flowing pressure calculating method}

To get the bottom-hole pressure through gauge measurement under pressure, the gas well need to be shut, which affects gas production and brings high costs. Due to the fact that some gas wells are difficult to measure the pressure through gauge, calculation of bottom-hole pressure of work needs to be done, including well-head pressure calculation method used, well density conversion of iterative method, pressure gradient, method of vertical pipe flow (throttle).

Density of iteration method. This method calculates the bottom-hole flowing pressure through the casing pressure, which based on the pressure distribution along well. Well pressure at any point in the tuning-casing annulus as follows: $p_{i}=p_{i-1}+\rho_{i-1} g h \times 10^{-6}, i=2,3, \cdots, n$; When $i=1, p_{1}=P_{c}$; When $i=n, p_{n}=P_{w f}$. The relationship of actual density of natural gas $\rho_{t}(t, p)$ and standard dry air composition of gas density $\rho_{\text {atr-it }}(t, p)$ is $\rho_{i}=\gamma_{g} \rho_{\text {atr }-i}, \gamma_{s}$ is natural gas relative density. $\mathrm{G}$ is gravitational acceleration, $\mathrm{g}=9.8 \mathrm{~N} / \mathrm{Kg}, \mathrm{h}$ is iterative step, $\mathrm{m}$.

Casing-tubing annulus at any point in the density increases with pressure, temperature and humidity, and pressure and temperature as the depth increases. Air density is a function of pressure and temperature ${ }^{[1-3]}: \rho_{\text {air }}(T, P)=\rho_{0} \frac{273.15}{273.15+T} \frac{P-0.0378 P_{P}}{0.1013}, \quad \rho_{\text {air }}$ is state air density $\mathrm{Kg} / \mathrm{m}^{3}$ of the temperature $T$, pressure $P$, and relative humidity $\phi ; \rho_{0}$ is state the density of dry air of the temperature for $0{ }^{\circ} \mathrm{C}$, pressure $0.1013 \mathrm{MPa}, \rho_{0}=1.293 \mathrm{Kg} / \mathrm{m}^{3} ; P_{b}$ is the partial pressure of water vapor in the air of 
temperature for $\mathrm{T}$ Saturated $(\mathrm{MPa}) ;{ }_{\text {is }}$ the relative humidity of air $(\%) ; P$ is absolute pressure (MPa); $\mathrm{T}$ is the temperature $\left({ }^{\circ} \mathrm{C}\right)$ 。

Iteration method of calculating bottom-hole pressure density is as follows:

$$
\left\{\begin{array}{l}
p_{1}=P_{c}, \rho_{1}=\rho_{0} \frac{273.15}{273.15+T} \frac{p_{1}-0.0378 \phi P_{b}}{0.1013} \gamma_{g} \\
p_{2}=p_{1}+\rho_{1} g h \times 10^{-6}, \rho_{2}=\rho_{0} \frac{273.15}{273.15+T} \frac{p_{2}-0.0378 \phi P_{b}}{0.1013} \gamma_{g} \\
p_{3}=p_{2}+\rho_{2} g h \times 10^{-6}, \rho_{3}=\rho_{0} \frac{273.15}{273.15+T} \frac{p_{3}-0.0378 \phi P_{b}}{0.1013} \gamma_{g} \\
\vdots \\
p_{n}=p_{n-1}+\rho_{n-1} g h \times 10^{-6}, \rho_{n}=\rho_{0} \frac{273.15}{273.15+T} \frac{p_{n}-0.0378 \phi P_{b}}{0.1013} \gamma_{g}
\end{array}\right.
$$

Method of vertical pipe flow. For Wells, the gas flows from the bottom of the tubing to the wellhead has the following 3 Features:

There is no work input and also no power output from end of tube to head;

To the flow of gas, the kinetic energy loss relative to the total energy loss is negligible.

Gas flow is vertical flow.

Combined gas flow formula, formula can get pressure with depth:

$$
\frac{1}{0.03415 \gamma_{g}}\left(\frac{Z T}{p}\right) d p+d H+1.324 \times 10^{-18} \frac{f}{d}\left(\frac{q_{s c} T Z}{p d^{2}}\right)^{2} d H=0
$$

$\gamma_{g}$ is the relative density of gases; $z$ is gas deviation factor; $\mathrm{T}$ is temperature; $\mathrm{H}$ is depth; $q_{s c}$ is the open flow; $\mathrm{p}$ is the corresponding pressure; $f$ is moody friction coefficient, $\mathrm{d}$ is the tubing diameter (m), Re is the coefficient of Renault. $\frac{1}{\sqrt{f}}=1.14-2 \log \left(\frac{e}{d}+\frac{21.25}{\operatorname{Re}^{0.9}}\right)$.

For a static gas column, $q_{s c}=0$, the bottom-hole pressure Eq. (2) simplified to:

$$
\int_{p_{1}}^{p_{2}} \frac{Z T}{p} d p=\int_{H_{1}}^{H_{2}} 0.03415 \gamma_{g} d H
$$

Calculating methods of mean temperature and mean deviation coefficient (static gas column)

Assuming $T=\bar{T}, Z=\bar{Z}$, Namely annual temperature and gas deviation factor is considered constant. It used average temperature of shaft $\bar{T}$ And the average deviation of coefficient $\bar{Z}$ instead of $Z$ and $T$. That is the $\mathrm{Z}$ and $\mathrm{T}$ have no relationship with pressure, so the Eq. (4) is simplified to:

$$
p_{w s}=p_{t s} \exp \left(\frac{0.03415 \gamma_{g} H}{\overline{T Z}}\right)
$$

$p_{w s}$ is method of static gas column pressure (MPa); $p_{t s}$ is the wellhead of the static gas column pressure $(\mathrm{MPa}) ; \mathrm{H}$ is the depth of wellhead gas reservoir in Central, $\mathrm{m}$; Average temperature in wellbore $\bar{T}^{\bar{T}=\left(T_{s s}+T_{w s}\right) / 2} ; \quad T_{w s}$ is bottom respectively, $T_{t s}$ is the absolute temperature, $\mathrm{K}$.

Cullender-Smith (flowing gas column)

$$
\begin{aligned}
& \text { Left of Eq. (3) multiply }\left(\frac{p}{Z T}\right)^{2}, \text { Set }^{F^{2}}= \\
& \int_{p_{1}}^{p_{2}} \frac{\frac{Z T}{p} d p}{1+\frac{1.324 \times 10^{-18} f\left(q_{s c} T Z\right)^{2}}{d^{5} p^{2}}}=\int_{p_{1}}^{p_{2}} \frac{\frac{p}{Z T} d p}{\left(\frac{p}{Z T}\right)^{2}+\frac{1.324 \times 10^{-18} f q_{s c}{ }^{2}}{d^{5}}}
\end{aligned}
$$

$\mathrm{H}$ (well depth) can be divided into $\mathrm{N}$ parts. $p_{i}$ is pressure, ${ }_{i}$ is the depth, ${ }^{i=1,2,3, \cdots, N+1}$. Set $I_{i+1}^{(0)}=I_{i},{ }_{i+1}=p_{i}+\frac{0.03415 \gamma_{g} H / N}{I_{i}}$. $p_{i+1}$ were iterative calculated according to ${ }^{I_{i+1}=} \frac{Z_{i+1} T_{i+1}}{p_{i+1}}$, until the next two results meet the precision. Simpson integration integral formula or other variants integral can also be used apart from the trapezoid formula or using. 
Bottom-hole flowing pressure model considering throttle. Based on throttling process characteristics, mathematical model divides the process into 3 study part: chokes the entrance suddenly shrink, respectively (Fig. 1 Section 1 To the throat), parameter and choke the throat chokes sudden expansion (Fig. 1 Section 2 To section 3 Section).

A variable Mach number was referenced. The MA was defined as the ratio of the flow field velocity $\mathrm{v}$ and the sound of gas $\mathrm{c}$ at any point:

$$
\begin{aligned}
& \mathrm{Ma}=\frac{v}{c} \\
& \mathrm{c}=\sqrt{k \frac{p}{\rho}}
\end{aligned}
$$

$\mathrm{k}$ is the adiabatic index; $\mathrm{c}$ is the sound of the gas, $\mathrm{m} / \mathrm{s}$.

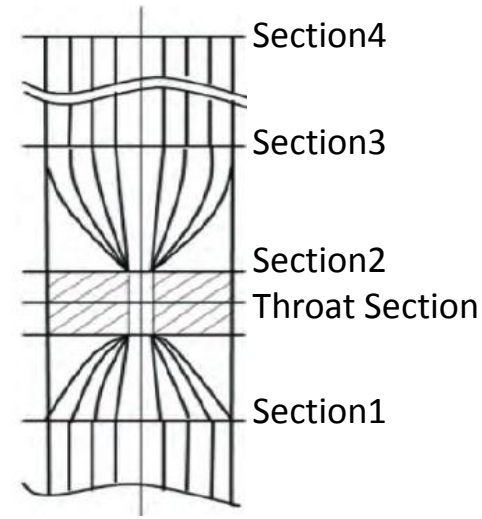

Figure 1 Throttle diagram

If the Mach number of section 2 is less than 1, section 2's Mach number is equal to the Mach number at the throat section, based on the principles of aerodynamics. If it exceed 1, it indicates the state of flows is in a supercritical state. Finally, the Mach number of choke at the throat section is 1 , Which can calculate bottom-hole flowing pressure.

Conversion of surface pressure gradient method.Conversion of surface pressure gradient method is based on production data which has a plenty of shut-in wellhead pressure recovery on the basis of information obtained after wellbore pressure gradient and the empirical formula of the wellhead pressure, portal pressure conversion based on formation pressure. This method is practical, but accuracy formulas depend on data accuracy and richness. Pressure gradient accuracy and shut-in restoring duration is the surface casing pressure of wellhead pressure conversion methods of two key points. The principle and the method of calculation is very simple, but it is more difficult to grasp two key points, which directly affect the accuracy of the formation pressure.

If shut-in pressure and single well controlled pressure are the same for a long time, the entire formation pressure will be kept balance, simply taking advantage of portal pressure and pressure gradient calculation of bottom hole pressure.

And wellhead pressure of wellbore pressure gradient:

$$
D=A P_{w h}+B
$$

D Is the pressure gradient; ${ }^{{ }_{w h}}$ Is the surface casing pressure, A Is the slope of the fitted, B Is the fitted intercept.

Using the surface casing pressure reduced formation pressure formula:

$$
P_{r}=P_{w h}+D \times H
$$

Which ${ }^{P_{r}}$ Bottom-hole flowing pressure, H Is depth, D Is the pressure gradient.

Calculation method of bottom hole liquid. When the liquid does not exist in the shaft, bottomhole pressure and oil pressure, casing pressure at the wellhead changed little for the gas well over a period of time. So it can calculate the depth of bore and casing surface based on the wellhead pressure difference between the appearing liquid before and after.

Fluid pressure before and after changes in the shaft calculation pipeline liquid-column height:

$$
h_{t t}=\frac{P_{t f 1}-P_{t f 2}}{\rho_{w} g \times 10^{-3}}
$$


-Casing annulus liquid level height for:

$$
h_{l c}=\frac{P_{c 1}-P_{c 2}}{\rho_{w} g \times 10^{-3}}
$$

The liquid column in the pipeline always exceeds the casing annulus liquid column for the gas well in the pipeline. The height difference between two liquid column can be calculated by the difference between the oil pressure and casing pressure at the same time, namely:

$$
\Delta h=\frac{P_{c 2}-P_{t f 2}}{\rho_{w} g \times 10^{-3}}
$$

Here: $\rho_{\mathrm{w}}$ For the liquid density, $1.01 \mathrm{~g} / \mathrm{cm} 3$; g For gravitational acceleration $9.8 \mathrm{~N} / \mathrm{Kg}$ 。 $\mathrm{H}_{\mathrm{lt}}$ for the fluid in the tubing height $(\mathrm{m}) ; \mathrm{h}_{\mathrm{lc}}$ for tuning-casing annulus liquid level height $(\mathrm{m}) ; \mathrm{P}_{\mathrm{tf} 1}$ as well when there was no effusion of wellhead hydraulic (Mpa); $\mathrm{P}_{\mathrm{tf} 2}$ for wellbore fluid wellhead pressure (Mpa); $\mathrm{P}_{\mathrm{c} 1}$ Wellbore when no fluid surface casing pressure (Mpa); $\mathrm{P}_{\mathrm{c} 2}$ Wellbore fluid surface casing pressure $(\mathrm{Mpa}) ; \Delta \mathrm{h}$ difference of liquid column height $(\mathrm{m})$. Effusions greater impact on the calculation of bottom hole pressure, so based on single well calculation pressure of fluid for each well has been corrected.

\section{Comparison of calculation method}

Comparison between several methods (Table 1) has been tested, the density of iterative method for calculating results and measured bottom-hole pressure close relative error is less than $10 \%$ 。 Method of vertical pipe flow and pressure gradient calculation error is large, relative error than the $30 \%$, Finally, the density of iterative method is choose as the method of calculating the bottom-hole pressure for the 48 block.

Table 1. Comparison between different methods for calculating bottom-hole pressure

\begin{tabular}{cccccccc}
\hline $\begin{array}{c}\text { Well } \\
\text { name }\end{array}$ & $\begin{array}{c}\text { Measured } \\
\text { bottom-hole } \\
\text { pressure } \\
\text { /Mpa }\end{array}$ & $\begin{array}{c}\text { Density of } \\
\text { iteration } \\
\text { /Mpa }\end{array}$ & $\begin{array}{c}\text { Relative } \\
\text { error (\%) }\end{array}$ & $\begin{array}{c}\text { Vertical pipe } \\
\text { flow } \\
\text { (throttle)/MPa }\end{array}$ & $\begin{array}{c}\text { Relative } \\
\text { error (\%) }\end{array}$ & $\begin{array}{c}\text { Conversion of } \\
\text { pressure gradient } \\
\text { /Mpa }\end{array}$ & $\begin{array}{c}\text { Relative } \\
\text { error }(\%)\end{array}$ \\
\hline $8-91$ & 23.48 & 25.40 & 8.18 & 27.22 & 15.92 & 16.45 & 29.94 \\
$17-34$ & 30.16 & 30.06 & 0.34 & 29.70 & 1.53 & 28.27 & 6.26 \\
$5-75$ & 19.50 & 21.00 & 7.70 & 27.59 & 41.48 & 19.49 & 0.04 \\
$21-65$ & 30.36 & 30.32 & 0.13 & 29.75 & 2.02 & 30.81 & 1.49 \\
$19-65 \mathrm{H} 2$ & 29.88 & 30.32 & 1.46 & 29.75 & 0.42 & 30.24 & 1.20 \\
$19-65 \mathrm{H} 1$ & 20.71 & 21.14 & 2.07 & 26.16 & 26.28 & 20.51 & 0.96 \\
$13-52 \mathrm{H} 2$ & 22.10 & 24.16 & 9.32 & 24.23 & 9.65 & 14.35 & 35.06 \\
\hline
\end{tabular}

\section{Conclusions}

Calculation of bottom hole pressure correction based on the solid height, can effectively reduce the calculation error, in calculation of wellbore liquid gas well bottom hole pressure,

Density iterative method is an effective method for calculating bottom hole pressure in 48 block of S gas field, it can be combined with bottom hole pressure measurement data to evaluate bottom hole pressure, gas field development.

\section{References}

[1]Zhang Xuanqi, Chen Wei, Li Jianpeng, density of iteration method to calculate bottom-hole flowing pressure. (Journal of Xian University (Natural science Edition), 2014).

[2]Liu wenjiang. Wet air density calculations . (Metering technology, 1985 )

[3]Zhao Shuhai. Understanding of the method of calculation of wet air density. (Hebei coal, 1999) 